\title{
Predicting students' performance using survey data
}

\author{
Catarina Felix' \\ REMIT, Universidade Portucalense, \\ LIAAD - INESC TEC \\ Porto, Portugal \\ cfo@inesctec.pt
}

\author{
Sonia Rolland Sobral' \\ REMIT, Universidade Portucalense, \\ Porto, Portugal \\ sonia@upt.pt
}

\begin{abstract}
The acquisition of competences for the development of computer programs is one of the main challenges faced by computer science students. As a result of not being able to develop the abilities needed (for example, abstraction), students drop out the subjects and sometimes even the course. There is a need to study the causes of student success (or failure) in introductory curricular units to check for behaviours or characteristics that may be determinant and thus try to prevent and change said causes. The students of one programming curricular unit were invited to answer four surveys. We use machine learning techniques to try to predict the students' grades based on the answers obtained on the surveys. The results obtained enable us to plan the semester accordingly, by anticipating how many students might need extra support. We hope to increase the students' motivation and, with this, increase their interest on the subject. This way we aim to accomplish our ultimate goal: reducing the drop out and increasing the overall average student performance.
\end{abstract}

Index Terms-student profiling, student performance, programming, machine learning, educational data mining 